\title{
Impact of Electronic Commerce on the Sporting Goods Market
}

\author{
Chao Zhou ${ }^{*}$ \\ School of Physical Education, Hunan University of Arts and Science, Changde 415000, Hunan, China
}

\begin{abstract}
With the ever-growing popularization and application of the Internet, the growing popularity of online shopping and e-commerce has made great progress, and the scope of future development is unlimited. The current rapid development of e-commerce has accurately grasped the current situation and future trends may also help in avoiding the obstacles in further promotion of the steady development of e-commerce. In various industries, e-commerce marketing model is used as a new way. In this paper, the status quo of the sporting goods industry is looked upon through research on the current application of e-commerce sporting goods industry and by conducting empirical research on the purchase through e-commerce of sporting goods consumers. E-commerce model analysis is then prepared under the influence factor that many consumers buy sporting goods, and propose targeted marketing strategies. Designed to guide enterprises to increase the number of domestic sporting goods e-commerce applications, efforts have been made to promote China's sports goods industry to enhance the overall performance and the overall competitiveness.
\end{abstract}

Keywords: E-commerce, sports marketing, strategic variation in sports marketing.

\section{ELECTRONIC COMMERCE}

Governments, academics, and businesses depending on the location, impact e-commerce from various angles and to varying degrees. It is believed that e-commerce refers to the Internet, Intranet and value-added network (VAN, ValueAdded Network)in electronic trading activities and related services, and is the traditional commercial activity of the electronic links and network [1]. Marketing is carried out through the creation of individual and collectiveoffers for sale and with the free exchange of products and values to obtain items needed social process It can be seen that the basic purpose of marketing is to attract customers, and increase market share and profits [2]. Increased corporate profits, depending on whether consumers buy the products, require that companies create products that meet the customers' demands, and also make it possible to achieve product sales. Ascustomers are willing to pay for the company's products, the company's production resources can be turned into profits. E-commerce and marketing are both connected and different; in the environment of e-commerce, marketing results in a series of advanced changes.

\subsection{Marketing Environment}

Changing consumer behavior and changing marketing environment eventually lead to changes in the marketing concept [3]. Traditional marketing concepts in terms of profits for the purpose of focusing on their own interests and the emergence of e-commerce development, promote the transformation of traditional business marketing concept.

*Address correspondence to this author at the School of Physical Education, Hunan University of Arts and Science, Changde 415000, Hunan, China; Tel: +86-13873644129; E-mail: 522892156@qq.com
The emergence of electronic commerce, breaking down the geographical differences, shortening the distribution time, has reduced the logistics. Consumers now have greater choice for costs as production and consumption e-commerce has facilitated both [4]. At this point, companies should adhere to the "people-oriented" purposes, concentrate on consumer demand and the primary purpose of improving customer satisfaction, pay more attention to individual consumers needs,.

\subsection{Changes in Consumer Behavior}

E-commerce as a new generation of corporate marketing environment has a significant impact, leading to changes in consumer behavior [5]. At one time, popularity of television had had a so-called "impact generation". However, since the rise of the Internet, many new media have sprung up in this environment contributing to Internet age consumers., This group of consumers make up the enterprise e-business environment [6], that is, the main target market. Such consumers are more receptive to new ideas and things, like individuality and the popularity of the network so that they can search for all the necessary items, without the need to leave their homes, in order to buy the best quality and most personalized products in the lowest prices.

\subsection{Marketing Concept}

Traditional marketing is mainly market-oriented, which involves market-based investigation of the case, to determine the marketing mix, and makes full use of resources in production to meet customer needs [7]. In the Internet era, in the context of e-commerce, companies are more committed to meet customer demands for personalized private customized services. According to the China Electronic Commerce Research Center (100EC.CN), monitoring data 
show that towards the end of 2013, Chinese e-commerce market transactions reached up to 10.2 trillion, by an increase of $29.9 \%$. Whereas, in B2B e-commerce, market transactions amounted to 8.2 trillion yuan, by an increase of $31.2 \%$. Online retail market deal size reached 1.8851 trillion yuan by an increase of $42.8 \%$. Fig. (1) presents Chinese ecommerce market size from 2009-2014.

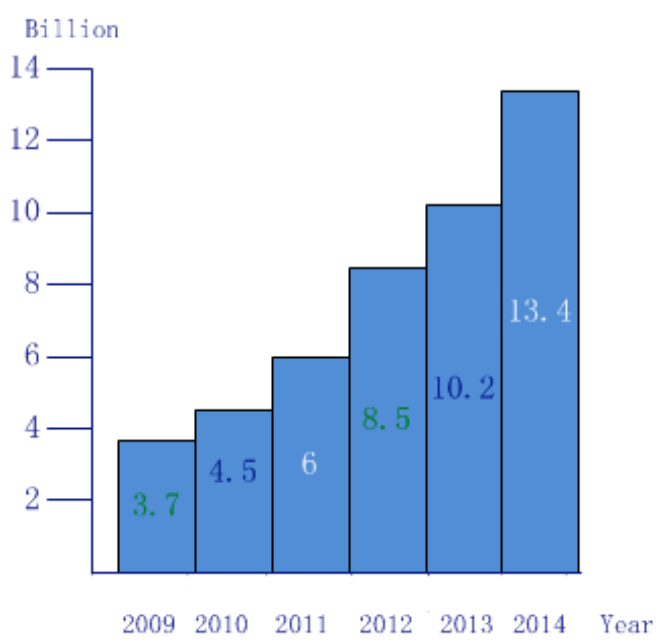

Fig. (1). 2009 - Chinese e-commerce market size in 2014.

\section{STATUS SPORTING GOODS INDUSTRY E- COMMERCE MODEL DEVELOPMENT}

With the development of Internet technology, ecommerce has been incorporated into people's daily production and all aspects of life, having a profound impact on economic and social development [8]. Especially, ecommerce and production activities, changes in production methods and production efficiency have played an extensiverole in the promotion of the sports market. In the sports marketing field, because of the network environment and network technology support, sporting goods businesshas undergone major changes, since the highest proportion of young Internet users, sports. The main goods companies target customers by using e-commerce [9]. According to the survey, as early as in 2001, $96 \%$ of US sporting goods companies were of the opinion that in the future for a long period of time, the enterprise business e-commerce will have a positive impact. According to Deutsche Bank, research report predicts that in China's personal consumption ecommerce market (including B2C and $\mathrm{C} 2 \mathrm{C}$ ), in the next five years, compound annual growth rate will reach $42 \%$ of the total market size in 2014 reaching 1.523 trillion yuan, accounting for 7.2 percent of total domestic retail sales. Accordingly, China's sporting goods companies are also actively using e-commerce marketing activities.

\subsection{Definition and Classification of E-Commerce}

E-commerce incorporates the use of computer technology, network technology and telecommunications technology, electronic, digital and network throughout the business process [10]. E-commerce generally refers to a wide range of business activities in the world, using the Internet for an open network application environment while browser/server, buyers and sellers of various business and trade activities interact and transact through the Internet online, enabling online shopping, online merchants between business model transactions, electronic payments and other online business activities and the associated integrated services activities.

E-commerce transactions in accordance with different objects can be divided into:

Business-to-Business, $\mathrm{B}$ to $\mathrm{B}$;

Business-to-Consumer, $\mathrm{B}$ to $\mathrm{C}$;

Business-to-Government, B to G;

Consumer-to-Government, $\mathrm{C}$ to $\mathrm{G}$;

Consumer-to-Consumer, $\mathrm{C}$ to $\mathrm{C}$;

According to empirical study, individual consumers were only studied for B2C and C2C e-commerce model.

\subsection{Sporting Goods Industry's Major E-Commerce Model Analysis}

Typically, there are two modes for carrying out ecommerce in major sporting goods companies, brand Direct mode and online delegate pattern [11]. Brand Direct Direct mode is similar to the form of physical retail stores, a selfbuilt plant by the brand platform that can sell products that can be $\mathrm{B} 2 \mathrm{C}$, and it may also be $\mathrm{B} 2 \mathrm{~B}$, or may be M2C (the factory to the customer); online entrusting mode product line entrusted to franchises or partners online sales. Formally, from the sale of e-commerce in the wholesale, retail, buy, purchase, spike, auction sales form, these types of sales efforts, customer segmentation, and time usage are very different.

\subsubsection{Sports Brand Independent B2C Website}

The number of sporting goods companies is difficult to simultaneously analyze all corporate websites of independent sports brands like Li Ning, Adidas, Nike, Puma and so on [11]. These brands are very well known sports brands as Li Ning Sports Goods companies belonging to the leader, have broader product categories successfully listed in Hong Kong, in 2008. Li Ning (Lining), Taobao and Tan Friends Network tripartite cooperation teamed up to launch an online store, entering the e-commerce development stage. In 2010, Li Ning official website launched online store, and optimized their official website. Li Ning further began a new online image of the Li Ning brand. Li Ning is also the only one with its own online store sporting goods business. Its subsidiary, otto, Double Happiness, a new dynamic, Kason appear in the navigation bar mall location, product classifications and activities close to real life. Li Ning Online Shopping Mall to support seven days no reason to return, more than three hundred cities nationwide cash on delivery, purchase of 280 postage, delivery method of home delivery, in the pass, EMS. Payment there Paypal, online banking online, quick money and cash on delivery [12]. Customer service using Live800 real-time online exchange system Ltd. Chengdu gold pin A, the customer simply click on the page icon in the conversation, and can directly contact the Web customer service for instant communication. Li Ning shop channel, there are three, one is authorized to Shop Direct introduced 

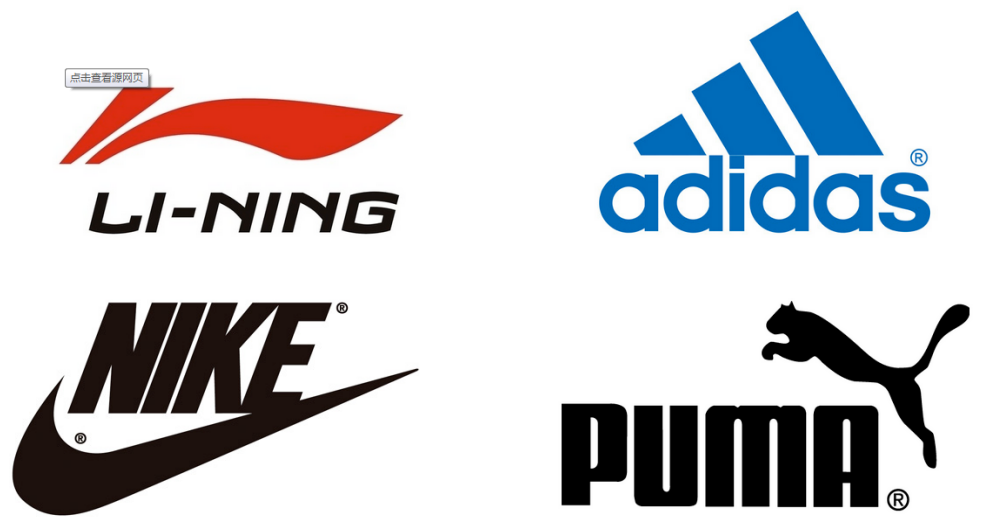

Fig. (2). Well-known sports brand logo.

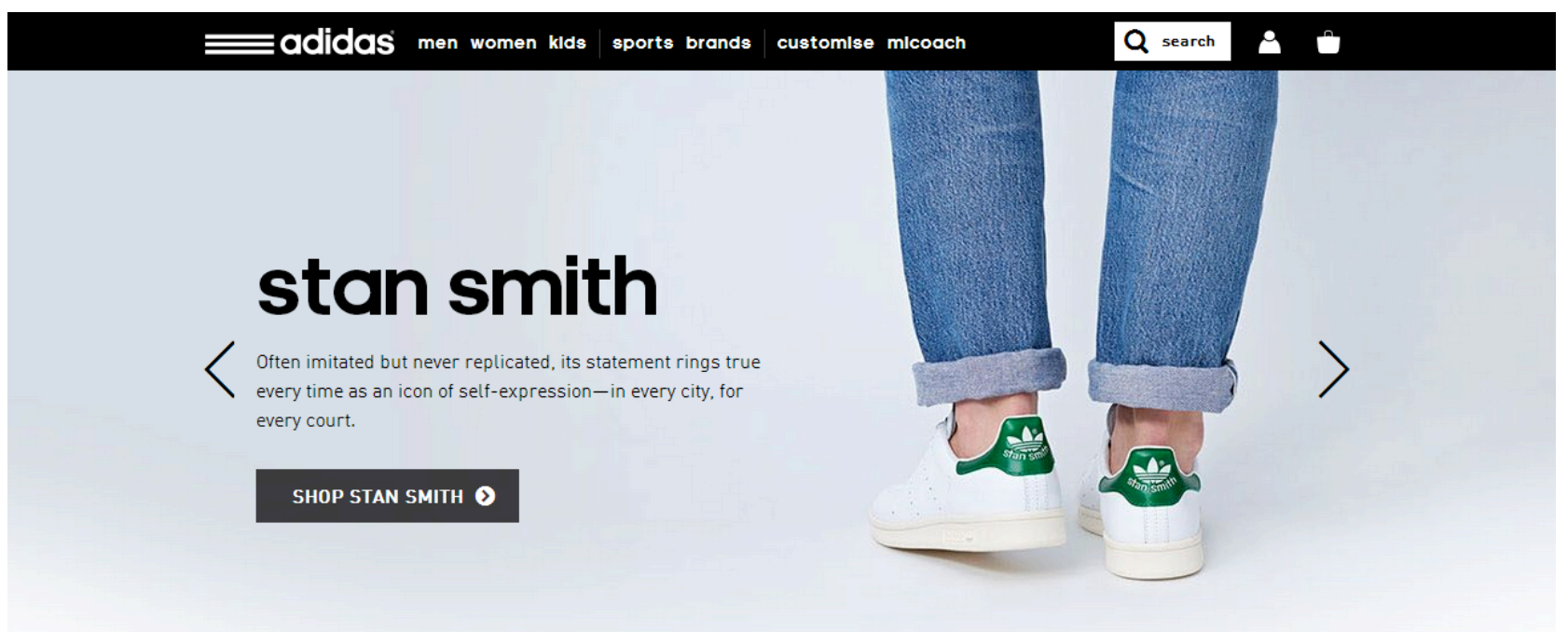

Fig. (3). Pathfinder official mall home figure.

above, remove outer own Shop Direct authorize construction of B2C website also Lynx Mall (Taobao Mall) outlets, pat Mall (Tencent) outlets and cool days.

Adidas is a German sports brand which sells its products to various countries by way of electronic mall sportswear and sports shoes. NIKE is the leading global sports brand. The company is headquartered in Oregon Beaverton, encompassing the production of sporting goods, such as clothing, footwear, sports equipment and so on. Nike also will be the world's leadingfootball and national soccer team jersey kit provider in various countries including Arsenal, Manchester United, Barcelona, Celtic, Juventus, Inter Milan, Brazil, the Netherlands, Portugal and the United States. In US on June 10, 2015, Nike was announced as the sole supplier of NBA apparel. Puma is from Germany and is known to produce shoes and sportswear based in large multinational corporations, 1998-2003 sports apparel market sales and profits of the fastest growing brands, the growth rate of 6 years more than two digits. In 1986, joined Munich and Frankfurt stock exchanges, to the end of 2007, there are 9,204 employees and selling products to over 80 countries. PUMA shoes and clothing in the hip-hop graffiti culture, in both the United States and abroad, have been extremely welcomed. PUMA along with adidas from the 1970 and 1980 s represents one thing, a well-known brand logo (Fig. 2).
Adidas is a German sports goods manufacturer withAdidas AG being a member company. Adidas with its founder Adolf - Dassler (Adolf AdiDassler), in 1920 began production of footwear near Nuremberg Herzogenaurach. In world football, it enjoys thesupport which any other sporting goods firm cannot match. Since the beginning of the 1970 World Cup, Adidas has become a FIFA official ball sponsor, providing their World Cup match ball after each session. Adidas endorses the European Cup, the Champions League, Bundesliga and other competitions and also all American Major League Soccer teams,to provide sports equipment and game ball. This corporate brand was ranked sixty-seventh in the World Brand Lab preparation of the "World Top 500 Brands" list. Fig. (3) shows the Adidas official store page.

\subsubsection{Miscellaneous Sporting Goods Online Store}

United States sports online store by the United States investment holding, specializes in sports, science and technology sports, extreme sports, electronic-business platform fashion sports and outdoor products sales and service. [13]. It is reported that by the end of 2010, inthe United States, the number of sports reached 369, a total of more than 30,000 kinds of products styles. Gome Holdings meaning the "United States Sports" has been playing "professional chain stores + vertical B2C website" as a new sport outdoor sporting goods "020" (Online 2 Offline, the 


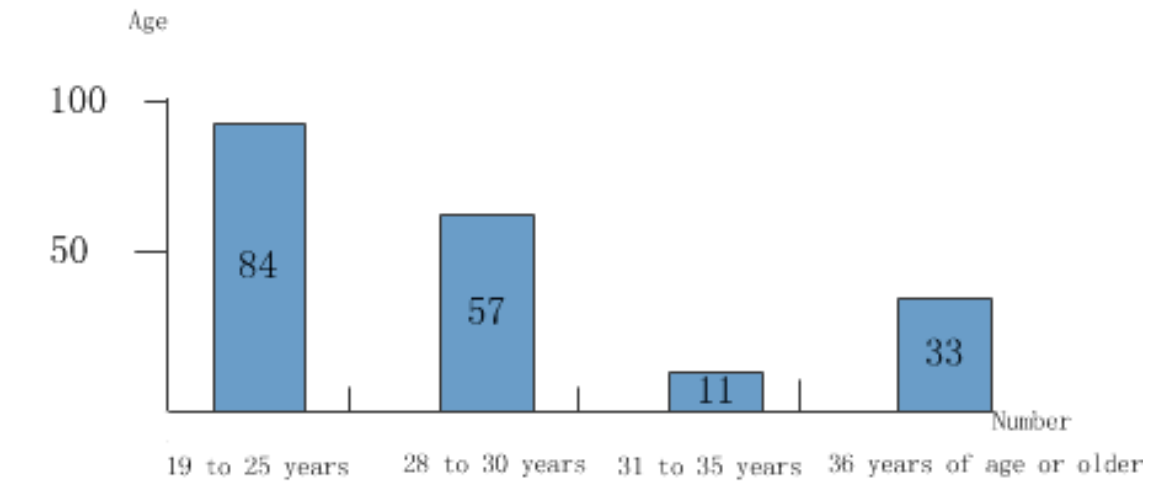

Fig. (4). Age statistics.

line and Internet business opportunities together through the Internet line Consumers on to real life - payline online goods, services, and then go on to enjoy the service line) stores.

From the current composition of Chinese Internet users point of view, at least 80 percent of Internet users agree to outdoor sporting goods sports core consumer population characteristics. Therefore, regardless of the domestic firstline or second-line sports and outdoor brands, all of the B2C business very seriously [14]. United States Sport online store and sports stores started simultaneously, so that online and offline channels, "seamless" converge, this "B2C website + chain stores" modeundoubtedly maximized the integration of business resources online and offline. In this sense, the United States Sports online store created a new milestone in China's e-commerce. Prior to that, regardless of Taobao, Dangdang, Jingdong or red children, Eslite, never started a B2C business line as the integration of online business model. Evaluation of the industry veteran said that the United States sports such that "020" e-commerce model represents the development trend of China's e-commerce business, but also a strong impetus to China's sports outdoor sporting goods market channel innovation process.

\subsection{Lack of Sporting Goods Industry E-Commerce Ap- plications}

Managers commerce application awareness of sporting goods business is weak. Sporting goods business managers lacking awareness of e-commerce can bring negative results to the development of enterprises. Many domestic sporting goods website designs are flashy. Basically, consumers browse the Web primarily to obtain product information, but Web designers often ignore the most basic things. The best entertainment parts must be more visually dynamic; however, the process of browsing productsis made too cumbersome which results in hasty browsing, thereby greatly reducing the brand image and the a decrease in online purchase and payment functions.

Sporting goods companies have a shortage of specializing talent in e-commerce [15]. Many sporting goods companies rely on specialized technology companies, and the lack of professional talent accumulation within the enterprise causes information flow by the company including the company's information technology hardware and software systems, database maintenance and updates and data collection, processing and dissemination. Therefore, evolving culture based on e-commerce of the international sporting goods market can become a serious problem for professionals.

\section{EMPIRICAL E-COMMERCE CONDITIONS SPORTS MARKETING STRATEGY}

Empirical study of consumer online purchase of sports goods in detail can help in the decision-making process. Access to relevant factors affecting consumers buying online sporting goods and the analysis of how these factors influence consumer buying behavior can provide the empirical basis for the development of appropriate marketing strategies.

The survey sample includes 102 men, and 83 women the age structure of respondents is: $45.4 \%$ 19-25 years old 84 people, the total number of survey; the total number of 26 surveys 57 to 30 years, $30.8 \%$ of the total number of investigations; $31-35$ years old 33 people, accounting for $17.8 \%$; $365.9 \%$ over the age of 11 , the total number of investigations. Fig. (4) is the age structure statistics.

According to the authoritative statistical bulletin, CNNIC shows that China's Internet users aged 20-29 is the highest percentage of all Internet users in the proportion of $29.8 \%$, while the participation of Internet users in this age group is also the greatest in online shopping. This study object concentrated on the age factor.

Since online shopping sporting goods consumers need to have some knowledge of computer networks, and often participate in sports, so, the survey was mainly conducted on higher education having higher awareness of online shopping. Most of the sample participants werecollege students, including those receiving college education and accounted for $21.6 \%$ (40) in which $49.2 \%$ were undergraduates (91) and graduate students accounted for 29.3 percent. Fig. (5) represents the education statistics.

Had to buy sporting goods in 119 individuals were selected to buy sports apparel (including sports shoes) class 84 people, choose to buy fitness equipment in 17 people choose sports equipment (including sports) of 28 people, choose another there are 15 people. Fig. (6) shows the consumer online shopping scale. 


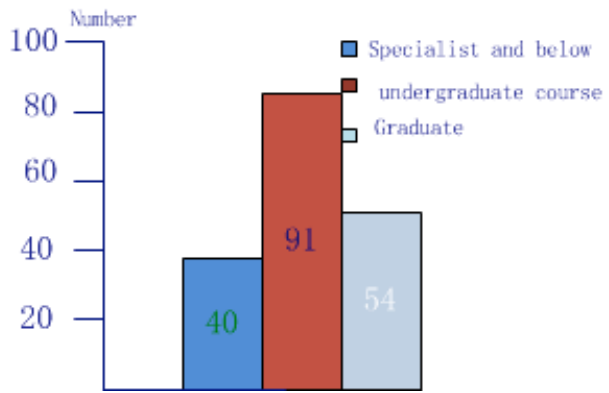

Fig. (5). Education statistics.

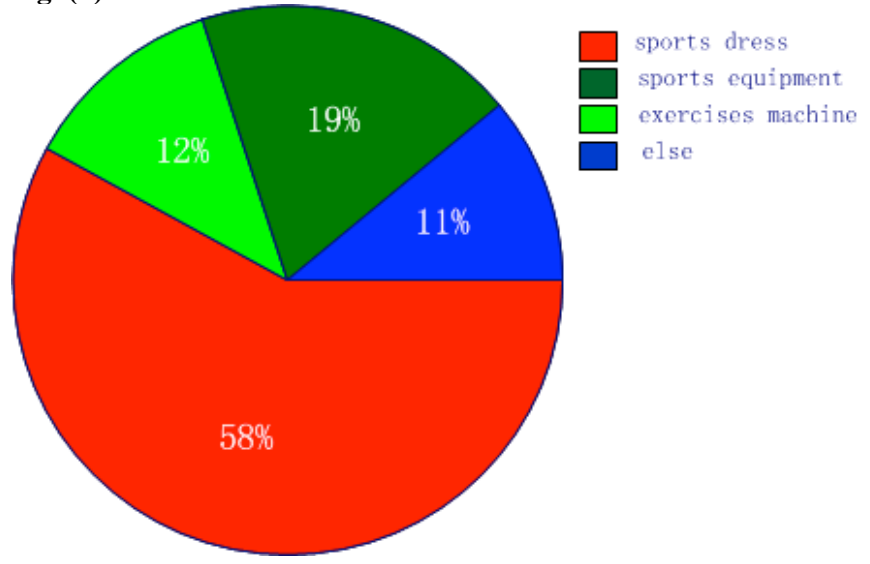

Fig. (6). Consumer online shopping sports types scale drawing.

According to the survey, even if consumers were satisfiedwith the sporting goods on one site, most likely they did not buy directly from the site. In the survey, 84 people after being satisfied with the sports purchased directly on the site, almost accounting for 45.4 percent of those surveyed. While 16 people were not even inclined to buy while 51 other people were seen satisfied with the goods afterwards, but did not necessarily purchase on the site. The most important reason affecting the purchase directly on the site was the quality of sporting goods, which was not followed by any hasty purchases by the consumers. This resulted in businesses to cut their prices or promotions. In addition, the business reputation and qualifications can be affected ifconsumers are not determined to buy an important factor.

There are 64 shopping sites or mode of payments affecting online shopping providing direct orders at the site, as consumers areable to undertake payment. Before consumers decide to buy sporting goods, customer service issues based on necessary exchanges between sellers and buyersand timely responses and good service attitude from the sellers, to some extent, affect the final purchase decisions of consumers. As in the survey, 94 people showed caring attitude of the seller facilitating effective communication .

Consumers are also very concerned about the way the goods are distributed as they do not want to buy the sporting goods which are lost or damaged during distribution, but at the same time, require goods in the shortest possible time in good condition, having easy access to them. There are many consumers abandoning the final purchase due to slow shipping or distribution issues. The distribution of goods was a concern to 79 people. Fig. (7) shows the product's outside factors.

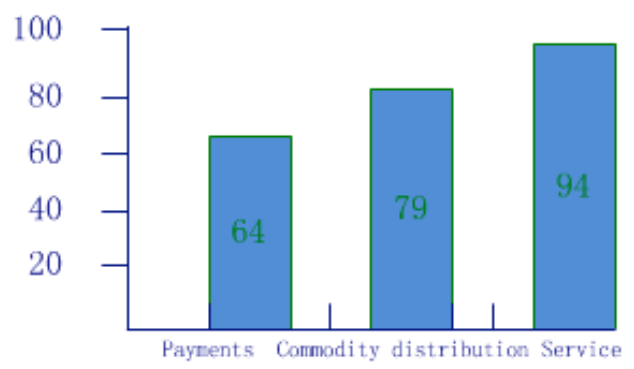

Fig. (7). Products factors.

\section{CONCLUSION FACTORS INFLUENCE SPORTING GOODS E-COMMERCE MARKETING STRATEGIES}

E-commerce model, different from the traditional business model, is an important feature: businesses and consumers no longer require places like a mall or store to trade, but have online stores or shops. In this shopping environment, sporting goods consumers themselves have made some changes in the corresponding e-commerce model.

According to empirical investigation, it can be seen that consumers buying sporting goods through the network of Internet users tend to have a certain cultural foundation, and it is easy for them to accept new things. Secondly, this fraction of consumers is often more interested in sports and physical education, and regularly participate in sportsand are more receptive to buy sporting goods online. In addition, consumers through online purchasing take the initiative of enhancing sports than the store when shopping, regardless of whether they purchase or not, as through a variety of ways they search the network and understand the relevant shopping information, and afterwards decide whether to buy or not.

When consumers buy sporting goods online, they have more autonomy as compared to when they traditionally buy sporting goods from stores, which is not susceptible to interference from external factors, such as physical stores staff persuasion, great contrast between the difficulty of the store, which means consumptionof net purchasing sports is stronger than the physical stores. When consumers complete online shopping, and receive the goods, they usually have the basic information to evaluate shopping, that is if the main contents of product information are consistent with thesporting goods description, including the size of the goods, appearance, texture and the overall shopping experience and other information. Product evaluation information has important implications for Internet buyers and sellers: it helps consumers to evaluate all aspects of ecommerce shopping site that is, test application effect; help sellers improve and optimize business model further improve the service attitude; also offer potential consumers with constructive suggestions, while sellers develop the next marketing strategy based on the evaluation information; furthermore, the merchant service attitude, quality of service, goods distribution and other content evaluation are also improved. All this can serve as an important basis for businesses to establish credibility and can increase the seller's reputation, expanding their influence and scale. 
Moreover, communication with the seller can enhance the viability and reliability of the sports market. When consumers are in the shopping process and have any questions about the goods, they can instantly use communication tools and shop the mall customer service dispensers and have one on one exchange negotiations to get a satisfactory answer. After the transaction, the consumer can also have timely instructions on the use of sporting goods from the seller.

\section{CONCLUSION}

Currently, the sporting goods industry is showing interestin developing online channels; online to offline growing trend development can help the brand achieve value and popularity. Single commodity marketing channels can not meet the practical needs of business and consumer ecommerce development. E-commerce continuing to evolve for small sporting goods industry is both a rare opportunity and a great challenge. For the creation of the brand to be successful, sporting goods companies should pay attention to the coordinated development of both online and offline stores, and continuously explore marketing strategies to meet consumer demands, follow the trend of social development while sparing heritage, momentum, in order to challenge the internationally renowned sports brand strength.

\section{CONFLICT OF INTEREST}

The author confirms that this article content has no conflict of interest.

\section{ACKNOWLEDGEMENTS}

Declared none.

\section{REFERENCES}

[1] E. Turban, D. King, and J.K. Lee, Overview of Electronic Commerce/Electronic Commerce, Springer International Publishing, Switzerland, 2015, pp. 3-49.
[2] P.V. Hande, D. Ghosh, and A. Govil, "A comparative study on factors shaping buying behaviour on B2B and B2C E-Commerce platforms in India", Journal of Marketing and Consumer Research, vol. 8, pp. 53-58, 2015.

[3] R. Virvalaite, V. Saladiene, and R. Bagdonaite, "Peculiarities of impulsive purchasing in the market of consumer goods", Engineering Economics, vol. 62, no. 2, pp. 101-108, 2015

[4] E. Turban, D. King, J.K. Lee, T.-P. Liang, and DC. Turban, Social Commerce: Foundations, Social Marketing, and Advertising, Electronic Commerce, Springer International Publishing, 2015, pp. 309365.

[5] A. Cook and T. Goette, "Mobile electronic commerce: what is it? who uses it? and why use it", Communications of the IIMA, vol. 6 , no. 4, p. 4, 2015.

[6] L. Einav, T. Kuchler, J. Levin, and N. Sundaresan, "Assessing sale strategies in online markets using matched listings", American Economic Journal: Microeconomics, vol. 7, no. 2, pp. 215-247, 2015.

[7] P. Sainam, S. Balasubramanian, and B.L. Bayus, "Consumer forwards: concept and empirical analysis of a sports ticket market", International Journal of Sport Finance, vol. 10, no. 2, p. 103, 2015.

[8] M. Mascarenhas, "Online sport consumption: Influence of consumers' motivations and concerns on their actual behavior and future purchase intentions", Universidade de Lisboa, 2015.

[9] E. Turban, D. King, and J.K. Lee, Retailing in Electronic Commerce: Products and Services//Electronic Commerce, Springer International Publishing, 2015, pp. 103-159.

[10] M.E. Gonzalez, G. Quesada, and J. Davis, "Application of quality management tools in the evaluation of websites: The Case of Sports Organizations" The Quality Management Journal, vol. 22, no. 1, p. $30,2015$.

[11] A. Israel, and M. Jakobs, "Germany: Challenges from New Online Practices to Established Competition Law Principles", European Competition Law \& Practice, 2015, p. 34.

[12] R. Guo, Cross-Border Economic Development and Cooperation, Cross-Border Management. Springer Berlin Heidelberg, pp. 301321, 2015.

[13] R. Hoye, A.C.T. Smith, and M. Nicholson, Sport Management: Principles and Applications, Routledge, UK, 2015.

[14] S. Pandey, D. Chawla, and U. Venkatesh, "Online shopper segmentation based on lifestyles: an exploratory study in India", Journal of Internet Commerce, vol. 14, no. 1, pp. 21-41, 2015.

[15] G. Cheng, and C. Yu, E-commerce Model Canvas in 3D Virtual Space: An Application in British Museum LISS 2013. Springer Berlin Heidelberg, 2015, pp. 17-28.

Received: June 10, 2015
(C) Chao Zhou; Licensee Bentham Open.

Revised: July 29, 2015

Accepted: August 15, 2015

This is an open access article licensed under the terms of the (https://creativecommons.org/licenses/by/4.0/legalcode), which permits unrestricted, noncommercial use, distribution and reproduction in any medium, provided the work is properly cited. 